\title{
EM RESPOSTA A "ISTO NÃO É BOM O SUFICIENTE": REFLEXÕES SOBRE A PESQUISA EM EDUCAÇ̃̃O AMBIENTAL NO CANADÁ EM CONTEXTOS DE EXPANSÃO'
}

Paul Hart*

RESUMO: Este artigo tem o propósito de oferecer um panorama da pesquisa em Educação Ambiental, da perspectiva canadense, no contexto da América do Norte. Desse ponto de vista, procuro, embora de forma perigosa, representar alguns pesquisadores e educadores canadenses que trabalham com Educação Ambiental ${ }^{2}$ e que escrevem sobre suas atividades, especialmente aqueles que responderam ao meu pedido de ajuda para a articulação de ideias a respeito do que está acontecendo e do que podemos falar sobre direções e possibilidades para o futuro em relação às nossas investigações atuais. Reconheço minha posição relativamente privilegiada nesse processo e também as limitações desse tipo de representação. Aceitei então a responsabilidade de explorar territórios de investigação que, a meu ver, parecem capturar, embora com várias lacunas, algumas reflexões e ideias que têm sido produzidas recentemente entre pesquisadores canadenses. Reconhecendo o caráter oscilante dos discursos no legado histórico de questões conceitualmente controversas e direções variadas, tento simplesmente localizar trajetórias que sugerem lampejos e aberturas para pensar e debater o global e o local na pesquisa em Educação Ambiental, com base em minha perspectiva como pesquisador que vive e trabalha no contexto da educação e da Educação Ambiental canadenses.

Palavras-chave: Pesquisa em Educação Ambiental; Contextos de Pesquisa em Educação Ambiental; Educação Ambiental e Campos de Investigação.

\section{IN RESPONSE TO "IT'S JUST NOT GOOD ENOUGH!": \\ THOUGTHS ON CANADIAN WORK WITHIN EXPANDING CONTEXTS OF ENVIRONMENTAL EDUCATION RESARCH}

ABSTRACT: The purpose of this paper is to provide an overview that traces a range of work on environmental education research from a Canadian perspective within a North American context. This viewpoint attempts dangerously to represent a number of explorations of Canadian environmental education researchers and practitioners, who write about their activities and, in particular, those who responded to my request for help in coming to articulate ideas about what is going on and what we may say about directions and possibilities for the future in respect of our current inquiries. I recognize my relatively privileged position within this process as well as the limitations of this form

\footnotetext{
* Professor of Science and Environmental Education; University of Regina, Canada. E-mail:paul.hart@uregina.ca
} 
of representation. So, I have accepted the responsibility of exploring landscapes of inquiry that seem to me to capture, albeit with many gaps and missing intentions, some thoughts and ideas that have been produced recently amongst Canadian researchers. Recognizing the changing nature of the discourses amongst the legacy of history across conceptually contested points and varied directions, I attempt simply to locate trajectories that suggest possible insights and openings for thinking and debate on the global and local in environmental education research, from my perspective as a researcher living and working within Canadian education and environmental education. keywords: Environmental Education Research; Contexts of Environmental Education Research; Environmental Education and Fields of Enquiry.

\section{Introdução}

Onde quer que seja encontrada, a pesquisa em Educação Ambiental é sustentada por vários discursos e práticas fortemente arraigados em orientações e estruturas modernistas. Ela é formada por pressupostos referentes ao que importa como meio ambiente, educação e pesquisa. Conforme argumentei há quase vinte anos, as questões que confrontam a Educação Ambiental no Canadá - e, consequentemente, a pesquisa em Educação Ambiental - estão inseridas numa variedade de condições educacionais e sociais que afetam a pesquisa e o desenvolvimento nesse país (HART, 1990). O currículo e a pedagogia permanecem como questões locais ou provincianas, do mesmo modo que os contratos e subsídios de pesquisa mais circunscritas, os quais, em geral, são autorizados por departamentos provincianos e outras fontes locais. As maiores fontes de subsídio à pesquisa educacional estão situadas, federal e academicamente, no Conselho de Pesquisa de Ciências Sociais e Humanidades (Social Sciences and Humanities Research Council ou SSHRC). E, embora os Subsídios Regulamentares para Pesquisas (Standard Research Grants) angariados por essa agência de base governamental sejam outorgados pelos pares em competição aberta, iniciativas cada vez maiores de estratégias de subsídios são direcionadas a questões específicas por meio de uma estrutura de comitê do governo federal. Nos últimos anos, essas estruturas subsidiárias significaram que um grupo seleto de educadores ambientais recebeu fundos em decorrência de iniciativas ligadas à sustentabilidade e, especificamente, às mudanças climáticas.

Ademais, diferenças regionais/territoriais estão presentes em políticas de bilinguismo, multiculturalismo e igualdade. E, a despeito de muitos anos de crítica de políticas e de mudança metodológica, as práticas 
oficiais de currículo continuam funcionando no modelo de pesquisadesenvolvimento-difusão-adoção de mudanças educacionais, o que pressupõe abordagens tradicionais baseadas em pesquisa de controle de qualidade e responsabilidade. Dados esses padrões e tendências estabelecidos para a pesquisa e o desenvolvimento no Canadá, a Educação Ambiental continua integrada a uma relativa obscuridade dentro de sistemas maiores de questões educacionais, tendo sua situação sido agravada pela resistência à mudança nos níveis locais e pelos complexos estratos de uma burocracia governamental que muda permanentemente. Mesmo diante desses problemas estruturais, os pesquisadores canadenses de Educação Ambiental participam ativamente de organizações e conselhos locais e regionais, bem como de redes nacionais (por exemplo, a Rede de Comunicações e Educação Ambiental - Environmental Education and Communications Network, EECOM) e colaborações internacionais (por exemplo, a Associação Norte-Americana de Educação Ambiental - North American Association for Environmental Education, NAAEE). A professora Lucie Sauvé é responsável por uma Cadeira de Educação Ambiental na Universidade de Quebec, em Montreal. Ao lado de Bob Jickling, da Universidade Lakehead, ela coordenou o $5^{\circ}$ Congresso Mundial de Educação Ambiental, realizado em Montreal, em maio de 2009. Com raízes na Rede da Biosfera e do Homem Canadense (Canadian Man and the Biosphere Network, MAB-Net), pessoas como Chuck Hopkins prepararam pesquisadores e educadores em Educação Ambiental em eventos nacionais e internacionais (por exemplo, a ECO-ED ${ }^{3}$ ) e, recentemente, em Centros de Especialidade, por meio da Universidade das Nações Unidas. A maior parte das universidades canadenses é formada por pesquisadores e estudantes que, cada qual a seu modo, trabalham local e globalmente, a fim de contribuir para a pesquisa em Educação Ambiental.

Ao explorar tendências e perspectivas na pesquisa em Educação Ambiental canadense, encontrei várias linhas de pensamento ao longo de uma gama de questões referentes a problemas e potencialidades. A Educação Ambiental é altamente variável: tem sido representada de muitas formas e mudou, talvez sem rumo, nos últimos vinte anos. O que uma vez foi descrito como detentor de um propósito revolucionário de transformação de valores humanos, em contraste com a preservação da ordem social vigente, foi pós-brundtlanizado ${ }^{4}$ numa variedade de expressões, como Educação para o Desenvolvimento Sustentável (EDS), 
denotando relações recíprocas e interativas da economia e da ecologia. Essa mudança conceitual e semântica mostrou-se politicamente interessante em diversos pontos.

Em primeiro lugar, o escopo e a substância da Educação Ambiental/Educação para o Desenvolvimento Sustentável (EA/EDS) influenciam a pesquisa no que toca a ideia de se e como o meio ambiente é experimentado nas salas de aula ou inculcado nos alunos em outros locais destinados à aprendizagem. A variação de como a Educação Ambiental é entendida, de como o conhecimento é conquistado e de como as abordagens pedagógicas são moldadas é algo que pode ser visto como fonte de preocupações ou de possibilidades, dependendo do ângulo adotado. Hoje os educadores ambientais podem recorrer a análises mais estruturadas dos processos pelos quais a consciência, a sensibilidade e a preocupação ambientais são geradas e usadas, além de atentarem para os contextos socioculturais em que a participação ocorre. Entretanto, observadores casuais da Educação Ambiental no Canadá podem argumentar que tal variabilidade diluiu a atividade da EA/EDS nas escolas em posicionamentos mais incertos e precários.

Em segundo lugar, as novas abordagens no campo da pesquisa em Educação Ambiental denotam uma mudança de base epistemológica em direção a modos mais expansivos e sobrepostos de pensar o meio ambiente na pedagogia como algo centrado em espaços e lugares sociais e culturais. Esses novos processos de investigação desafiam noções simplistas sobre o que é válido como objeto do conhecimento e dão mais destaque ao modo como as experiências em Educação Ambiental deveriam ser situadas. Diferentes modos de conceituar a relação entre educação e investigação apontam o valor da pluralidade nas experiências e no trabalho para remover a condição adjetival da Educação Ambiental, enfatizando o caráter central do meio ambiente no pensamento e no conhecimento, que são elementos basilares do currículo e da política social.

Em terceiro lugar, os discursos internacionais (LOTZ-SISITKA, 2004) têm dado destaque a certas questões culturais relativas aos contextos social e educacional no Canadá, nos quais a pobreza, a opressão e a marginalização revelam engajamento social em diversas comunidades de aprendizes. A pesquisa em Educação Ambiental está trabalhando para convidar crianças (BLANCHET-COHEN, 2008) e diversos grupos (por exemplo, aborígines) para diálogos sobre o que é válido como conhe- 
cimento nos contextos em que questões de justiça social e ambiental são importantes. Um tema comum nessas novas áreas de investigação da Educação Ambiental é a necessidade de (re)enquadrar a pesquisa e a pedagogia, de modo a enfocar o entendimento do contexto sociocultural que engloba as questões educacionais de ensino e aprendizagem e as relações aí existentes quanto à natureza e aos produtos que podem emergir rumo a um senso de autoidentidade e aprendizagem social. Essas perspectivas oferecem muitas lentes para a observação das questões contemporâneas no contexto das históricas estruturas discursivas que estão sendo desafiadas por jovens pesquisadores ativistas com base no momento intergeracional - isto é, as práticas, crenças e estruturas educacionais associadas a circunstâncias locais e a condições sociopolíticas.

Em quarto lugar, os contornos eternamente em debate da pesquisa em Educação Ambiental nunca estiveram mais em pauta, já que agora as novas tecnologias e as imagens da educação no contexto da globalização nos desafiam a alargar nossas noções de investigação.

Os pesquisadores de Educação Ambiental são cada vez mais desafiados pelas tarefas um tanto esquizofrênicas de negociar entre visões mais complexas de investigação diante das resistentes políticas e estruturas educacionais modernistas que também são responsáveis pelo financiamento das pesquisas. Os pesquisadores canadenses de Educação Ambiental esforçam-se para atuar em algum ponto entre o terreno de expansão intelectual que caracteriza a investigação educacional através do NAAEE e do Grupo Especial de Interesse em Educação Ambiental e Ecológica, este último pertencente à Associação Americana de Pesquisa Educacional, e o terreno dos subsídios do órgão federal SSHRC, cujos focos estratégicos são as práticas-padrão. Como se pode abordar uma atividade escolar que seja capaz de influenciar o trabalho docente e as experiências dos alunos de modo satisfatório e produtivo em meio às divisões de ordem socioeconômica?

Por fim, Mayer-Smith e Bartosh (2009) sugerem que, embora estejam altamente dispersos na literatura e sejam difíceis de consolidar na perspectiva canadense, há vivos diálogos focados em questões de justiça social, conhecimento indígena e tradições feministas entre pensadores, escritores, filósofos e pesquisadores de Educação Ambiental no Canadá. Esses diálogos estão crescendo e já começaram a afetar os elaboradores de políticas nos departamentos de educação (FAZIO; KARROW, 2009). 
A preocupação quanto à maneira política como o foco na sustentabilidade é traduzido na prática, a necessidade de mais tradução da teoria para a prática e a pressão de questões ambientais muito concretas encontradas diariamente na mídia canadense terão implicações subsidiárias para a educação referente ao meio ambiente no Canadá.

Embora seja difícil precisar a influência da pesquisa em Educação Ambiental, conforme atestam os recentes encontros do Congresso Mundial de Educação Ambiental (por exemplo, em Montreal, 2009) e os seminários internacionais (por exemplo, Montebello, Canadá, 2009), seu crescimento e sua promessa são certamente bem mais mensuráveis. Como esse corpo de trabalho crescente e heterogêneo continua proporcionando lampejos e levantando novas questões, além de gerar novos quadros, o contexto da pesquisa em Educação Ambiental, a despeito de suas contestações e contradições, parece, a meu ver, estar se voltando para níveis mais profundos de significado e aumentando a importância de praticantes e teóricos do meio ambiente e da sustentabilidade. Talvez o tradicional binômio teoria/prática esteja cedendo lugar ao pensamento de como a investigação liga ambas. Parece prudente pensar sobre discussões atuais de pesquisa no contexto sociopolíticohistórico da pesquisa em Educação Ambiental no Canadá e então atravessar fronteiras nacionais, mas à luz de entendimentos maiores sobre como a Educação Ambiental tem sido utilizada de forma conceitual e prática em caminhos mais específicos quanto à região e à comunidade (MCKENZIE, 2009). Reconhecendo a complexidade dessas múltiplas dimensões, que agora devem fazer parte das nossas investigações, destaco alguns esforços recentes para conectar a pesquisa e o ensino, que trabalham para dissolver sua própria distinção. Por fim, indicarei algumas possibilidades teóricas para imaginar como a pesquisa em Educação Ambiental poderia aproveitar tradições variadas para informar de modo mais explícito nossos progressos e programas.

\section{Contextos da pesquisa em Educação Ambiental no Canadá}

A controvérsia em torno da natureza e do propósito da pesquisa em Educação Ambiental pode ser encontrada nas resenhas de pesquisa que, segundo meu entendimento, atrelaram os pesquisadores canadenses 
a diversas bases teórico-metodológicas. Metodologicamente, ocorreu uma transformação profunda nos últimos vinte anos: passou-se de uma perspectiva predominante de ciência aplicada de base quantitativa (cf. IOZZI, 1981; MARCINKOWSKI, 1990) para linhas de investigação baseadas numa variedade de perspectivas interpretativas, críticas e marcadas pelo prefixo pós- (cf. HART; NOLAN, 1999; PALMER, 1998). Questões sobre o princípio e a qualidade dessa base de investigação alargada no contexto da pesquisa em Educação Ambiental estão agora sob um ativo debate filosófico, num conjunto de periódicos e publicações em crescente expansão. São os tipos de questão sobre objetivos fundamentais e sobre orientação metodológica que só podem ser abordados mediante sérios debates sobre filosofia, ideologia e interesse (BONNETT; ELLIOT'T, 1999).

Esses debates tornam-se habituais em nossas discussões no cenário da pesquisa em Educação Ambiental canadense, conforme ilustrou o seminário de pré-conferência ocorrido na conferência canadense da EECOM ("Trilhas da Sustentabilidade"), realizada em Kananaskis, Alberta (maio de 2007). As apresentações variaram desde propostas para engajar as crianças em ambientes naturais por meio do teatro (MACKLIN; HVENEGAARD; JOHNSON, 2007) e questões sobre como os estudantes são influenciados por programas de estudo de terras alagadas (REMPELL, 2007), ou imagens/experiências positivas/ negativas (FLOWERS, 2007), ou ainda experiências espirituais (HEINTZMAN, 2007), até explorações de teoria de construto pessoal (KOOL, 2007), educação biocêntrica (BAKER, 2007) ou investigação ecológica (BARKER, 2007), além de abordagens voltadas à aprendizagem e à sustentabilidade ambientais. Vê-se claramente que os pesquisadores de Educação Ambiental canadenses estão engajados em diversas áreas de investigação e que estas buscam entender como nossas identificações com esferas entrelaçadas de lugares, culturas e identidades pessoais afetam as nossas orientações para o socioecológico em todos os níveis de teoria e prática educacional (cf. MCKENZIE, 2008).

Ao longo da última década, tentei verificar se determinadas constelações de atividade de pesquisa estão relacionadas ou direcionadas à investigação sobre Educação Ambiental no Canadá ou no exterior (HART, 2008; HART; NOLAN, 2009). Algumas delas parecem permanecer conspícuas e se tornaram quase familiares, embora haja sinais recentes de mudanças necessárias e tensões à vista. Em meu papel como 
editor da Revista de Educação Ambiental (Journal of Environmental Education) e da Revista Canadense de Educação Ambiental (Canadian Journal of Environmental Education, CJEE), percebi algum descontentamento com as orientações e perspectivas-padrão na investigação sobre Educação Ambiental. Por exemplo, um tipo de tradição referente a um comportamento ambientalmente correto ligado a conhecimentos e atitudes ambientais permanece manifesto através de algum espectro de trabalho canadense. Assim como suas contrapartes internacionais, os pesquisadores canadenses foram além das premissas originais, a fim de provar entendimentos do que essa relação pode de fato significar para pessoas de todas as idades, como parte de um complexo conjunto de percepções, valores, emoções que constituem o modo como construímos nossas subjetividades em relação a questões de justiça social e ambiental (CHEAK; VOLK; HUNGERFORD, 2002).

Algumas frustrações com a aparente preocupação com o que poderia ser chamado de problema de precisão no contexto da literatura de conhecimento-atitude-comportamento (SMITH-SEBASTO, 2000) resultou na expansão da quantidade de investigação em vários sentidos, desde tentativas de aumentar o rigor no enquadramento quantitativo das investigações até uma variedade de abordagens qualitativas. Dos anos $1990 \mathrm{em}$ diante, os pesquisadores canadenses, tanto quanto os de outros países, consideraram útil abordar uma grande extensão de questões, usando metodologias evocativas em meio a um misterioso arranjo de perspectivas teóricas (cf. SAUVÉ, 1999). Atualmente, é comum observar investigações etnográficas de cunho crítico ou pós-estruturalista, bem como estudos de fenomenologia hermenêutica transformados em análises do discurso ou ações participativas de pesquisa-ação talvez com interesses críticos e revestimentos pós-coloniais, pós-estruturalistas e pós-modernos desses interesses metodológicos. Tais estudos podem aparecer na forma de estudos culturais, de classes sociais, de raças ou feministas, ou ainda como estudos de temática "queer", lésbica, bissexual ou transexual (GLBT) ou envolvendo outros interesses isolados ou combinados. Podemos antecipar uma diversidade crescente no interesse metodológico e na consequente exploração metodológica, já que recém-graduados das universidades canadenses expandem nossas noções do que importa como conhecimento, como investigação legítima e como evidências e formas legítimas de representação (cf., por exemplo, BARRETT, 2009). 
Como se poderia esperar, a pesquisa em Educação Ambiental está intricadamente ligada a variações dentro da pesquisa educacional, das investigações sobre o currículo, da pesquisa em formação de professores, do desenvolvimento profissional e dos estudos sobre alunos em espaços formais e não-formais (museus, centros de ciências). Por exemplo, estudos que pretendem localizar a Educação Ambiental nos currículos das escolas e universidades (MAYER-SMITH; BARTOSH, 2009), estudos de caso que tentam identificar os propulsores e os obstáculos para a Educação Ambiental em todos os níveis do sistema educacional (FAZIO; KARROW; ANDRACHUK, 2008), bem como estudos sobre a avaliação do currículo e da implementação da Educação Ambiental cujo intuito é explorar como a EA/EDS pode ser situada. Diversas metodologias, como a pesquisa-ação (PRUNEAU, 1995), o estudo de caso (ULIANA, 1996) e a investigação narrativa (HART, 2003), têm caracterizado esse tipo de pesquisa. Contudo, na última década, parece-me que surgiu uma tendência de preterir estudos embasados em quadros metodológicos específicos em favor de quaisquer aplicações de métodos e metodologias que possam auxiliar o entendimento de questões transversais, como participação e aprendizagem, processos de identidade/subjetivação e cultura em contexto pedagógico, além de várias influências de discursos dominantes sobre práticas de Educação Ambiental.

Nos contextos canadense e norte-americano, também encontramos comunidades de investigadores que têm como foco as questões internacionais e que parecem ter assumido a responsabilidade de trabalhálas de maneiras complexas quanto aos seus significados locais. Com base em minhas leituras sobre ênfases de pesquisa em periódicos de Educação Ambiental não publicados em inglês, tentei retratar algumas conexões e constelações em relação aos diagramas a seguir. Os pesquisadores canadenses de Educação Ambiental estão implicados direta ou indiretamente em todo o espectro de interesses de pesquisa representado por tais ilustrações. Se por um lado qualquer tentativa de representação é limitada, por outro ela busca capturar a linguagem de pesquisa relacionada a determinados programas de pesquisa, como descrito por autores cujos trabalhos foram apresentados em periódicos sobre Educação Ambiental, tais como Pesquisa em Educação Ambiental (Environmental Education Research) e Revista Canadense de Educação Ambiental (Canadian Journal of Environmental Education). Acredito que há a necessidade de reconhecer a proliferação de 
novos periódicos, como a Teoria e Práxis Verde: Revista de Ecopedagogia (Green Theory and Praxis: The Journal of Ecopedagogy). Essas publicações e os novos formatos eletrônicos disponíveis oferecem novos e diferentes focos de investigação que estimularão a discussão e o debate sobre a reconstrução de categorias e rótulos de outras formas igualmente legítimas. De todo modo, as áreas de investigação indicadas nos conjuntos aqui apresentados podem proporcionar aos leitores internacionais algumas indicações de tendências a respeito desse terreno cada vez mais complexo chamado pesquisa em Educação Ambiental.

A Figura 1 representa o que considero tanto eventual quanto predominante na literatura da pesquisa em Educação Ambiental como conjunto de áreas de investigação. Discussões e debates em fóruns canadenses (EECOM), norte-americanos (NAAEE) e internacionais ( $5^{\circ}$ Congresso Mundial de Educação Ambiental, Montreal, 2009) agora passam a lidar com áreas de destaque que vão além do debate definitório em curso sobre EA/EDS e dos diálogos paradigmáticos de outrora. Cada um desses nódulos é guiado por interesses de pesquisadores, de modo que, por exemplo, determinados debates sobre pedagogia crítica ou autobiografia podem relatar estudos sobre a aprendizagem de crianças. $\mathrm{O}$ interesse na dimensão socioecológica da EA/EDS pode revelar como certas universidades veem seu trabalho interdisciplinar em EA/EDS, ao passo que o interesse em ecoturismo pode dar suporte a estudos desses tipos de experiência. Não há muitas conexões entre as várias áreas de investigação porque as (inter-)relações são bastante complexas e multidimensionais.

O segundo conjunto de interesses de pesquisa é menos tópico e mais focado em questões de pesquisa maiores que são do interesse de pesquisadores canadenses e norte-americanos. Há interseções óbvias - e, creio eu, necessárias - nos tópicos da Figura 1, mas talvez em níveis diferentes de complexidade, revelando e ocultando diferentes questões metodológicas e teórico-conceituais. Os pesquisadores de Educação Ambiental precisaram, cada vez mais, pôr em prática as questões conceituais que utilizam para descrever seus interesses. Por exemplo, um interesse na relação entre as experiências de crianças na natureza e a consequente sensibilidade ambiental (qualquer que seja o seu significado) é mais provável de ser inserido na linguagem que caracteriza um conhecimento mais complexo de consciência social embasado em experiência de lugar. Tais noções de consciência social e de lugar são elas 
próprias conceitos controversos na medida em que encobrimos ideias críticas e pós-modernas sobre espaço e discurso. À luz de seus quadros e discursos subjacentes, os debates e discussões de pesquisa na literatura da Educação Ambiental são, em geral, assim como o discurso canadense, mais cuidadosamente embasados do ponto de vista filosófico, embora de certa forma tornem-se complicados pela inconsistência e pelos jogos de palavras destinados a desmontar a maioria das coisas que, nas nossas investigações, pensamos que sabemos. É assim que deveria ser nos quadros de investigação governados pelo trabalho da crítica reflexiva em múltiplos critérios de julgamento da qualidade.

$\mathrm{O}$ que me parece evidente a respeito da comunidade canadense de pesquisa em Educação Ambiental é o compromisso de entender a diversidade de pensamentos, ações e culturas que caracteriza uma nação multicultural. Tendo em conta que as metodologias de pesquisa se desenvolvem para abarcar mais do que dimensões cognitivas de questões complexas, atingindo uma variedade de perspectivas mais sensíveis às relações de poder, às emoções, à construção da experiência e às questões de posicionamentos de valores culturais e morais, a investigação em Educação Ambiental parece estar adquirindo características de reflexividade crítica que indicam certa maturidade do campo, o que o torna apto a trabalhar através de ambiguidades necessárias, categorias desordenadas e questões de representação e a pôr em prática argumentos que vão além do método e da metodologia em termos de dimensões discursivas/ideológicas/filosóficas que orientam a investigação.

\section{Terreno controverso e novas direções}

Nos últimos vinte anos, a Educação Ambiental ganhou proeminência crescente nos discursos canadenses sobre educação como parte do currículo escolar, a despeito da intensificada preocupação com os modelos que demandam ênfase renovada em habilidades básicas. Embora um tanto tênue, um foco da pesquisa em Educação Ambiental em resposta à justificativa do seu mandato é evidente na educação norteamericana (cf. LIEBERMAN; HOODY, 1998). No Canadá, a agitação intelectual provocada pela Consulta Nacional sobre Educação Ambiental e Sustentabilidade (1999-2002) (CANADA, 2002), apresentada no 
Encontro Mundial sobre Desenvolvimento Sustentável, em Johanesburgo (setembro de 2002), pode ter feito mais pela pesquisa em Educação Ambiental do que pareceu à primeira vista. Ao alterarmos a linguagem para a aprendizagem ambiental, parece-me que, por qualquer razão que seja, nós alteramos o questionamento de todo o esforço educacional relacionado ao meio ambiente que não se enquadrava em modelos, como, por exemplo, medidas de habilidade cognitiva, designadas por um pesquisador ambiental de "ouro de tolo" (GRINDSTAFF, 1987, p. 47). A linguagem da "Estrutura" desviou o foco para a consideração de valores e modos éticos de pensar, para a recuperação da sabedoria e do conhecimento tradicional dos aborígines, para a experiência pessoal em termos de pertencer a um lugar na comunidade e no ecossistema, para a consciência intergeracional, por intermédio de abordagens disciplinares e múltiplas formas de conhecimento. É possível que nunca saibamos como a mudança ocorre no sentido de um campo reunir propósitos, mas, a despeito de recentes chamadas para práticas baseadas na evidência e da necessidade de os sistemas educacionais responderem às ondas de conservadorismo regional e nacional, não sem as poderosas influências americanas, os pesquisadores canadenses de Educação Ambiental começaram a fornecer respostas por meio de estudos sobre a dinâmica embaralhada de salas de aula e de culturas reais, fazendo com que as fronteiras de suas investigações se alinhassem às suas formas de ver e saber.

O movimento da pesquisa em Educação Ambiental ao longo do tempo serve tanto como pano de fundo quanto como voz no diálogo com a história de pesquisa desse campo, a qual, conforme ficou evidente no recente seminário internacional sobre pesquisa em Educação Ambiental realizado em Montebello, Quebec, proporcionou novas visões sobre o que importa como EA/EDS e questionou do que e como a Educação Ambiental e suas formas de investigação são conceituadas. Do meu ponto de vista, os pesquisadores canadenses de Educação Ambiental estão encerrados nas lutas educacionais globais para entender que diferenças coisas como educação fizeram ou podem fazer. Poder-se-ia dizer que nós (isto é, o campo de pesquisa) estamos reativando o discurso, examinando nossos posicionamentos (dos quais derivam nossas investigações) e chegando a questionar nossas consciências ou nossos quadros de pensamento. Estamos olhando e buscando direções de mudança e o modo como isso foi construído de diferentes formas. Fizemos isso várias 
vezes no campo da pesquisa em Educação Ambiental, enfocando valores e significados mais profundos, como visões de mundo que implicam epistemologias e metodologias (cf. ROBOTTOM; HART, 1993). No entanto, o terreno mudou: visões críticas e pós-estruturalistas de posicionamento, postura e construção discursiva agora movem as bases do campo (e a nós que nele estamos inseridos). Trabalhar dilemas envolve examinar como nossos discursos culturais nos predispuseram a (re)interpretar como poderíamos fazer diferentes perguntas e fazer perguntas diferentemente (cf. ST. PIERRE, 2000; WESTON, 1996; 2005).

A tipologia de Sauvé sobre diferentes concepções de educação é um exemplo de como poderíamos caracterizar ou esmiuçar o passado e nos posicionar para questionar o futuro. Entretanto, há ainda outros tipos de questão a serem considerados quanto à invisibilidade social da Educação Ambiental (e da pesquisa em Educação Ambiental), a qual foi entendida como uma espécie de fracasso do nosso trabalho e investigação em vez de uma prática mascarada em meio às hierarquias socioeducacionais, discursivamente moldada para preservar relações de poder. Apesar da sua existência relativamente curta, a Educação Ambiental e a pesquisa nesse campo engajaram-se em tarefas que desafiam de modo mais sério nossas histórias e nossos subtextos sagrados. Interrogando essencialismos discursivos de regimes culturais dominantes no cenário global das culturas, questionando o reforço de normas universalizantes e desconstruindo as políticas de nomeação (por exemplo, EA/EDS), além de desafiar múltiplos quadros de metodologias de investigação, colocamos esse campo de pesquisa nas suas raízes filosóficas. Reconhecer as representações de ontem reificadas como as más representações de hoje não é um trabalho fácil. Nós, no papel de educadores ambientais, examinamos agora de que modo estamos implicados nos contornos de retórica familiar como construções sociais explicadas por certas perspectivas (STEVENSON, 1987; 2007).

No contexto da pesquisa em Educação Ambiental, nossas práticas metodológicas canadenses foram reconhecidas - apesar de isso ter ocorrido com uma dose necessária de ceticismo - como catalisadores para repensar os métodos de pesquisa em "contradição intencional" (MCKENZIE, 2004) de sua constituição discursiva. Pesquisar dessa posição envolve formas "em busca", processos de "ver que quadros 
estamos vendo" daquelas ficções teóricas peculiares que enquadram nosso trabalho (LATHER, 1991). Assim, a pesquisa em Educação Ambiental, juntamente com a pesquisa em educação, chegou a utilizar a construção social da EA/EDS enquanto diminuímos o ritmo (PAYNE, no prelo) para refletir sobre o passado e (re)imaginar novos espaços discursivos. Como indicou Wilson (2006) sobre a educação de base artística, nós estamos fazendo uso do tráfego globalizado de invisibilidade, a fim de que ele possa ser localizado e atraído para alguma subjetividade. Ao unirem essas subjetividades a ideias socioculturais, os pesquisadores canadenses de Educação Ambiental e suas contrapartes internacionais poderão agir cataliticamente através das fronteiras, de maneira a revelar e perturbar as arqueologias não vistas de formato cultural para nosso trabalho colaborativo de reposicionamento (cf. DAVIS; HARRÉ, 1990).

\section{(Re)posicionando:}

\section{aprofundando a complexidade do nosso trabalho de investigação}

Para Brunner (1998), um trabalho de reposicionamento permite o conhecimento do que se encontra fora do escopo da nossa própria identidade discursiva, como uma prática na prevenção da criação de novas ortodoxias. Permite-nos considerar mais seriamente nossos processos de subjetivação (DAVIES, 2006), num trabalho memorial e autobiográfico, em pedagogias de aprendizagem social, como aprendizagens experienciais e como exercícios nos processos de reconceituação da produção cultural em nossa atividade como pesquisadores. Permite-nos reconceituar o currículo como um texto fenomenológico e desconstruído, talvez das maneiras como Stevenson $(1987$; 2007) o retratou, em contraste com os discursos dominantes na América do Norte. Pode até mesmo nos permitir ver o que não conseguimos ver nos espaços cotidianos dominados por imagens culturais que se tornaram invisíveis na sua qualidade ordinária de senso comum. Pode ainda expor imagens midiáticas como se fossem interpretadas de modo a produzir pessoas em certas imagens e mascarar/marginalizar o que não se encaixa nas normas preconcebidas. Por exemplo, no trabalho que desenvolvo com imagens produzidas por crianças sobre o meio ambiente, tenho encontrado construtos deficientes 
de "infância" (termo emprestado da psicologia desenvolvimentista) num sistema educacional que foi projetado para "manufaturar" tipos ideais de cidadão (cf. HART, 2000). Por meio do reposicionamento ontológico, nós também efetuamos o reposicionamento epistemológico, de modo que determinados domínios curriculares (tais como Educação Ambiental, educação de base artística, educação física) que reconhecem o saber como um conjunto agregado, fora da mente e que é alcançado em interação direta com o mundo (ou seja, é experiencial), são novamente trazidos à tona. Isso requer uma reinterpretação do currículo com base em práticas pedagógicas transformadas que possam engendrar representação (por exemplo, BARRETT et al., 2005). A pesquisa em Educação Ambiental, reconhecida como mais estabelecida publicamente e como investigação participativa em relação aos nossos processos de subjetivação, é capaz de acionar essas formas de saber que não podem ser totalmente transmitidas pela linguagem (ELLSWORTH, 2005; PAYNE, no prelo).

No tocante a áreas curriculares marginalizadas, como a Educação Ambiental e a Educação Artística, parece frutífero para nossa investigação começar a tirar proveito dos mecanismos globalizados que tornam o currículo da Educação Ambiental invisível, a fim de que este seja localizado e colocado em espaços pedagógicos específicos, como aqueles referentes à educação informal (museus, por exemplo), funcionando como territórios onde os jovens possam construir os próprios textos e ler os de outros. No trabalho que desenvolvemos junto ao Fórum da Juventude sobre a Sustentabilidade (YFS), por exemplo, solicitamos a alunos e professores que realizassem mudanças de papéis com o fito de criar condições para estabelecer ativos diálogos críticos por meio da imaginação individual e de ideias socioculturais sobre ativismo ambiental e ensino tradicional, numa tentativa de tornar claras as arqueologias de cunho cultural não observadas (BARRETT et al., 2005).

Tendo em conta a natureza multicultural cada vez mais interessante da sociedade canadense, parece-me que a pesquisa em Educação Ambiental tem o papel de realizar reposicionamentos, empregando investigações colaborativas (isto é, de aprendizagem social) e narrativas (de autoidentificação) nos arranjos de poder que estruturam os papéis e as relações sociais dominantes. Esse trabalho de reposicionar as imagens de papéis e relações pode servir para reposicionar o sentido na pedagogia (cf. VAN MANEN, 1990) mediante autobiografias ou autoetnografias 
reinterpretadas que incluem trabalhos de narrativa sociocultural (fora do escopo do nosso trabalho de subjetividade) como novos espaços de resistência. Nesse sentido, a pesquisa em Educação Ambiental pode encorajar os educadores ambientais a explorar a abertura de espaços pedagógicos/curriculares nos quais os jovens possam começar a "ver" e a "conhecer" a si próprios no mundo, adotando um pensamento crítico sobre as histórias culturais sagradas, imaginando novas histórias e desenvolvendo meios criativos de explorá-las rumo à mudança.

Em diversos sentidos, a Revista Canadense de Educação Ambiental (CJEE) teve o papel de reposicionar a pesquisa em Educação Ambiental. Por exemplo, a tipologia de Sauvé (1996) sobre os diferentes conceitos de educação oferece quadros para que se vejam nossos próprios pressupostos subjacentes (como subtextos mais óbvios de nossas investigações). Por outro lado, um modo totalmente diferente de ver a pesquisa em Educação Ambiental, no que se refere à superação dos quadros existentes por parte dos trabalhos ecopedagógicos e culturais, pode ser encontrado na coleção editada por Greenwood e McKenzie (2009), dedicada sobretudo ao contexto, à experiência e à socioecologia. Minha exploração das contribuições de autores canadenses para a reconceituação do campo ao longo de quinze anos tem produzido vários tipos de questão que podem revolucionar globalmente a pesquisa em Educação Ambiental. Tais questões referem-se a ajustes rumo à mudança, seja mudança de consciência (BONNETT, 2006), de objetivos (SMYTH, 2006), de pensamento (de natureza crítico-social) ou ainda de processos educacionais (por exemplo, representação coletiva (STEVENSON, 2007)). A observação feita pela CJEE proporcionou muitas imagens discursivas do que parece estar acontecendo na pesquisa em Educação Ambiental enquanto os acadêmicos canadenses buscam tornar mais claras suas próprias ideias quanto ao que O’Donoghue e Russo (2009) denominam "modelos emergentes de abstração", no contexto das nossas ações de desenvolvimento destinadas à busca dos pesquisadores pela inteligibilidade (ST. PIERRE, 2000).

Em relação à CJEE, seria possível dizer que, embora se mostre um tanto regional ou nacional, proporcionou assertivas críticas e reflexivas sobre a hiperatividade de pesquisa de vários estudos triviais no largo campo da pesquisa internacional em Educação Ambiental; adicionou profundidade e substância às questões relativas a como os pesquisadores têm realizado seus trabalhos e ao que está acontecendo nas 
escolas, bem como nas cabeças dos alunos. A despeito de sua orientação algo filosófica, detém uma incrível praticidade. Traz à mente os debates sobre os Padrões Nacionais para a Educação Ambiental nos EUA ou ainda o debate de Sanera sobre lavagem cerebral, com base nos quais o editorial de Jickling nos ajuda a ter uma visão mais aprofundada sobre posicionamento local. Esse debate foi sabiamente justaposto numa única questão da revista contra um segundo grupo de artigos que explorava dimensões de investigação narrativa como uma forma de posicionamento epistemológico em aprendizagem (social) ligada aos aspectos relevantes da vida. Ao longo de todo o período de publicação dessa revista, a função de monitoramento discursivo, a meu ver, forneceu questões sobre a expansão das fronteiras do "que importa" e de quem determina o que importa.

Nos últimos cinco anos, vários artigos-chave da CJEE constituídos de perspectivas locais parecem ter lançado luz sobre questões que dizem respeito a estratégias de posicionamento. $\mathrm{O}$ trabalho de Jardine (2005) sobre o valor do engajamento sensorial e outros trabalhos sobre valores ambientais e transformação social, subjetiva e de valores (DYMENT; REID, 2005), lugar (CURTHOYS, 2007), ética narrativa (BAI, 2004; BLENKINSOP, 2006; HICKORY, 2004; JICKLING, 2004; ZANDVLIET; BROWN, 2006), letramento ecológico (LEDUC; WARKENTIN, 2006) e cidadania apostam na consciência social e na responsabilidade social para a mudança. Por exemplo, Leesa Fawcett (2000) escreve a respeito do valor de pensar sobre as pessoas em termos de teorias narrativas de identidade, metáforas e emoções. Essa perspectiva pode estar ligada à noção de Marcia McKenzie (2004) quanto ao fato de a contradição intencional ser uma importante posição epistemológica (uma forma concreta de saber) na investigação pós-estruturalista e feminista (cf. também BARRETT, 2005).

Adquirir mais consciência de que tais ideias estão relacionadas à cultura no sentido de uma reconceituação de conexões entre a natureza, a cultura, a educação e o meio ambiente parece significar o enfrentamento de questões de valor que formam a base da diversidade cultural e do caráter único do indivíduo, embora as concepções estabelecidas através de perspectivas pós-coloniais e estudos culturais permaneçam complexas e controversas. Muitos autores mostram-se preocupados com a possibilidade de que discussões sobre poder, raça, classe, gênero (cf. RUSSELL; SARICK; 
CHANDLER, 2002), habilidade, geografia, sexualidade, entre outros tópicos, forneçam as bases para novos campos teóricos, além de discussões sobre a prática e a ética de pesquisa. Por exemplo, as preocupações de Cheney (2002) com as histórias das primeiras nações canadenses no campo da pesquisa em Educação Ambiental têm implicações para o trabalho metodológico na história de vida/oral, na autobiografia e na autoetnografia.

\section{Como podemos tornar a pesquisa em Educação Ambiental um conjunto de campos de investigação}

Atualmente, temos na pesquisa em Educação Ambiental campos de investigação verde que podem lançar luz sobre uma larga variedade de questões metodológicas e conceituais. Em seu conjunto, o campo encoraja novas indagações sobre as práticas/discursos da Educação Ambiental e sobre a pesquisa em Educação Ambiental, além de propiciar grande variedade de formas de representação e legitimação. Periódicos como a CJEE nunca evitaram questões sociais críticas, tais como racismo e etnocentrismo; ao contrário, anteciparam-nas nas suas próprias lutas pela legitimação de um campo aplicado das ciências sociais e "humanas". Uma problemática-chave que surge é imaginar novas ordenações desses discursos, isto é, quais deles deveriam ser priorizados. Não há respostas fáceis. Desde 2004, tem sido desafiador observar os pontos de foco em meio à proliferação de paradigmas e problemáticas no campo da pesquisa em Educação Ambiental. Por essa razão, talvez, os periódicos dedicados à área tenham começado a enfatizar questões temáticas especiais que examinam mais profundamente as problemáticas de pesquisa no que tange às nossas intersubjetividades e abordagens participativas ao longo das fronteiras de pressupostos culturais, de estratégias metodológicas e da extensão das perspectivas filosóficas, desde o empirismo até o pósestruturalismo. Sauvé $(2005 ; 2007)$ continua a buscar tipologias mais complexas dessa rica e diversificada atividade. Outros pesquisadores, como Jardine (2005) e Barrett (2005), estão tentando compreender as epistemologias sociais e alargar o pensamento ontológico. Ian Robottom (2005) continua encorajando pesquisadores para que reenfrentem os debates diante dos fracassos das pesquisas para lidar com as exigências e contextualidades da prática. Nesse ponto, as questões sobre história, 
contexto, política e ética precisam estar embasadas em alguma forma de teoria social ou posicionamento filosófico, na medida em que se buscam prioridades para orientar a pesquisa.

Com respeito às preocupações no campo sobre a sua epistemologia social e metodologias diversas, a profundidade de pensamento e o engajamento filosófico com essas preocupações justificam uma atenção de ordem global. Podemos encontrar evidências de progresso na literatura: por exemplo, progresso no entendimento de como os pesquisadores de Educação Ambiental estão dotando o conhecimento de vida social com o objetivo de tornar o texto um elemento mais participativo na prática educacional. E embora possamos ter heranças distintas, conforme aponta Reid (2003), os pesquisadores de Educação Ambiental parecem ser do tipo que agrega ao invés de separar, de modo que suas diferenças tendem a se complementar e sempre adicionam uma parte do legado da Educação Ambiental à riqueza do nosso entendimento sobre a complexidade da mudança. Assim, juntos eles podem levantar questões sobre como a epistemologia da Educação Ambiental poderia ser mais estratégica, política e pragmática ou sobre como poderia ser mais democrática e participativa. Ao reconhecermos nosso recém-descoberto poder (inter-) relacional, que é sustentado pela nova teoria da aprendizagem, voltada aos processos de subjetivação e à análise do discurso, buscamos novas metáforas e epistemologias sociais mais apropriadas que possam colocar nossa teoria na prática, simultaneamente reconhecendo suas limitações nos quadros das pedagogias críticas e atentas à cultura.

Parece apropriado pensar sobre a substância do campo, assim como sobre as possíveis reviravoltas conceituais e críticas. Do meu ponto de vista, nós, que trabalhamos no Canadá, estamos imersos numa ação de equilíbrio político, uma situação em meio a outras, envolvendo pressões a questões locais e um largo arcabouço de metodologias e pesquisas que estão se formando e se transformando rumo a uma investigação socioecológica cujas forma e função situam-se nas redes de alianças capazes de mudar a face da educação e do que importa em termos de qualidade. Temos consciência da necessidade de enfrentarmos as difíceis questões filosóficas que podem nos ajudar a (re)conceituar o campo continuamente, mediante práticas e discursos envolvendo a natureza, a cultura, a educação e o meio ambiente. Temos, de fato, plena consciência da natureza prática de nosso trabalho, das nossas conexões com as 
políticas públicas, com as tecnologias e com o currículo, formados pelas estruturas de poder dos discursos dominantes. Ademais, reconhecemos nossas responsabilidades ao envolvermos jovens em decisões sobre o futuro. Estamos aprendendo a manter o foco em questões cruciais, como aprendizagem, conhecimento e existência, além de encararmos com seriedade as alegações que, no passado, muitas vezes, enquadraram inconscientemente nossas investigações.

$\mathrm{Na}$ tentativa de ler através do campo da pesquisa em Educação Ambiental, à luz de dez anos de experiência editando a revista Pesquisa em Educação Ambiental (Environmental Education Research), Reid e Scott (2006) reuniram coleções desse trabalho e outros artigos sobre pesquisa em Educação Ambiental. Eles decidiram selecionar artigos-modelo e solicitar comentários críticos, tendo em conta disposições metodológicas e ideológicas, bem como critérios de igualdade e justiça. As questões levantadas pelos editores e colaboradores sugerem problemáticas apontadas por pesquisadores canadenses de Educação Ambiental referentes a tensões entre justiça social e ecojustiça, diversidade metodológica e os fins da nossa investigação. As necessidades por eles identificadas aplicam-se a cada um de nós como acadêmicos reflexivos, sensíveis e responsáveis e incluem: permanecer aberto a visões não familiares, a outras tradições de conhecimento e a múltiplas perspectivas, bem como ser mais inclusivo, mais afetuoso, mais generoso e ao mesmo tempo ter coragem para ser mais criticamente reflexivo e franco nas discussões e nos debates. A pesquisa em Educação Ambiental, ao longo de todas as perspectivas de base nacional, precisa tratar de questões cruciais cujas dimensões são altruístas: entendimentos que passam por teorias, culturas e geografias, questões de natureza pedagógica, comunitária, local e real e processos de aprendizagem. Ao que parece, a linguagem está evoluindo impacientemente para a criação de condições que rejeitam qualquer complacência.

A atividade canadense na Educação Ambiental continua, em vários sentidos, dedicada a incluir o ecológico e ambiental em espaços curriculares controversos e a questionar as condições existentes de aprendizagem. Atualmente, a pesquisa em Educação Ambiental também trabalha para conectar espaços e locais de aprendizagem, entremeando consciência sociocultural com experiência intersubjetiva por intermédio de pedagogias expandidas e práticas críticas de pesquisa. Parece que reenfrentamos elementos da Educação Ambiental socialmente crítica (cf. 
ROBOTTOM; HART, 1993; ROBOTTOM, 2005) com complexidades intercruzadas em meio às críticas questões sociais relacionadas à educação. Essas complexidades advêm de campos multidisciplinares estudos culturais, educação cidadã, teoria racial crítica, teoria queer, perspectivas pós-estruturalistas e pós-coloniais, indigenismo, feminismo, deficiência - e de uma rede de crescentes preocupações interrelacionadas.

De acordo com minha interpretação desse complexo cenário, estamos aprendendo mais sobre como participar localmente e comunicar globalmente, indo além do que fazemos atualmente quanto à (re)conceituação das mudanças sociais e culturais na educação socioecológica e nos renovados contornos da ecopedagogia crítica. Estamos aprendendo a trabalhar nossas perspectivas individuais, teorias e pressupostos e a neles nos basear (já que é difícil conhecê-los), ao mesmo tempo que os traduzimos por meio da aprendizagem e da participação, sem deixarmos de manter a mente aberta para diferentes tipos de relação com os outros, incluindo outras espécies e o planeta. Ao termos mais experiências relacionais no âmbito educacional, podemos lidar ativamente com processos de transformação de condições opressivas (inclusive ambientais), valendo-nos de experiências crítico-cognitivas e concretas, que podem ser vistas como uma forma de alcançar mudanças sociais e culturais na realidade fundamental (isto é, re-habitação) (GREENWOOD; MCKENZIE, 2009; MCKENZIE, 2009).

Há um sentimento crescente em relação à pesquisa em Educação Ambiental no Canadá, uma crescente impaciência com e nesse campo que é cada vez mais suspeita de visões de desenvolvimento sustentável, envolvendo trocas econômicas no contexto de um mercado neoliberal que parece atravessar todos os partidos políticos. A Educação para o Desenvolvimento Sustentável passa a ser algo radicalmente diferente disso? $\mathrm{E}$ as conquistas do movimento em contextos que parecem incapazes de oferecer críticas sociais holísticas e alternativas culturais reais para o ciclo sem fim das economias políticas? Por que, em seu conjunto, o campo da Educação Ambiental não abraçou uma visão de mundo mais holística ou se associou a epistemologias mais transformadoras de diversos segmentos? Educadores ambientais críticos começaram a se perguntar se as instituições globais (ou seja, aquelas que os povoam) são capazes de imaginar limites para o crescimento. 
Os impacientes que estão entre nós, aqueles que associam a educação opressiva ao indivíduo, à sociedade, à cultura e ao ambiente, têm levantado questões incômodas. Essas questões vão desde geografias de opressão de classe, raça, sexo e de espécie até problemas sociais, como pobreza e deterioração dos padrões de existência para a maioria em virtude do crescimento contínuo da população do planeta. A despeito das iniciativas globais vindas de Estocolmo (1972), da Conferência das Nações Unidas para o Meio Ambiente e o Desenvolvimento (Earth Summit, 2002), da Carta da Terra (Earth Charter) e da Década da Educação para o Desenvolvimento Sustentável, além das iniciativas de organizações não-governamentais e trabalhos locais em universidades e escolas, e até mesmo da propaganda verde enganosa ${ }^{5}$ feita pela mídia e das verdades inconvenientes, parece que não atingimos as crises sociais em andamento. Nos nossos processos de investigação, parece que ainda não atingimos formas controversas de aprendizagem e práxis social que implicam mudanças nos sistemas educacionais formais por meio da Educação Ambiental. O Seminário de Montebello, realizado no Canadá, em 2009, levantou questões críticas das ecopedagogias contra formas reduzidas da Educação Ambiental, como pedagogia experiencial e pedagogia ao ar livre, as quais parecem lidar de forma acrítica com o conjunto de questões sociopolítico-culturais e pedagógicas que permanecem marginalizadas em programas e políticas de pesquisa, de formação docente e de liderança educacional.

É interessante que hoje, em 2009, considere-se que o ambientalismo, como força política dominante, esteja em risco de ser absorvido pelas estratégias globalizadoras de economias políticas orientadas ao crescimento, o que o torna incapaz de gerar o tipo de crítica holística e de alternativa cultural necessário para reverter a crise ecológica do planeta. As crescentes preocupações dos movimentos de base com as questões ambientais nos anos 1960 e 1970, as quais resultaram no envolvimento da Unesco com a Educação Ambiental, foram também fundadas em argumentos de que as abordagens educacionais convencionais distorcem os problemas ideológicos causados pela despolitização das questões ambientais. Em outras palavras, por trás de qualquer processo educacional encontra-se uma filosofia, geralmente implícita e baseada nos valores e interesses pessoais daqueles que estão no poder. A noção vigente era que a Educação Ambiental deveria olhar para além das realidades formadas 
por influências particulares a fim de levar em conta questões sobre como e por que a realidade é construída de tais modos. Portanto, é de fato interessante examinar a retórica a favor da Educação para o Desenvolvimento Sustentável presente nos documentos elaborados pela Unesco em iterações subsequentes do Relatório da Conferência das Nações Unidas para o Meio Ambiente e o Desenvolvimento (1992) e das reuniões realizadas em Johanesburgo (2002), bem como nos documentos da Década da Educação para o Desenvolvimento Sustentável das Nações Unidas (Undesd). Essa análise discursiva crítica parece crucial na medida em que os educadores ambientais continuam a avançar na reconceituação de sua área de atuação como um conjunto de formas críticas de ecopedagogias.

À maneira das críticas à tecnocratização da Educação Ambiental nos anos 1980 (ROBOTTOM, 1987), as mais novas dimensões de justiça social e ecológica, juntamente com uma política ecológica voltada para o futuro, estão trabalhando para (re)modelar o desenvolvimento da Educação Ambiental em termos de ecoletramento e formas culturalmente relevantes de conhecimento (ação orientada, participativa e empíricointerpretativa), sociais na sua teoria da aprendizagem e desconstruidoras dos textos culturais da EA/EDS. Como uma teoria crítica da educação, noções ecopedagógicas de Educação Ambiental trabalham dialeticamente para sustentar e criticar a EA/EDS como conjunto de formas hegemônicas de discurso educacional que, de vários modos, alarga e restringe a pedagogia, conforme valores de base ideológica. Pretendendo fazer intervenções estratégicas em nome dos oprimidos, que são representados de forma não crítica no contexto dos objetivos estabelecidos como modelares e das abordagens experienciais/ao ar livre, as formas ecopedagógicas de educação ambiental estão começando a evidenciar a ambiguidade da associação da Educação Ambiental com a educação formal. A pesquisa em Educação Ambiental, por meio de novas formas críticas que incorporam ideias dos estudos culturais, além de outras provindas de tópicos como raça, classe, gênero e perspectivas de base geográfica e sexual, tem aberto espaços para uma mudança interna (cf., por exemplo, GREENWOOD, 2008a; 2008b; MCKENZIE, 2008).

A meu ver, parece pouco interessante simplesmente apanhar o que está à mão (GRAY-DONALD; SELBY, 2008; REID, 2009) no âmbito da pesquisa em Educação Ambiental. Cada vez mais observamos 
interseções complexas de questões ecológicas e socioculturais através de lentes igualmente mais complexas, retrabalhadas e refinadas num calidoscópio de entrelaçamentos de perspectivas críticas, feministas, pósestruturalistas e culturais, perpassando culturas, espaços e lugares, questões de aprendizagem socioecológica e pensamentos expandidos sobre como investigar e mudar práticas. As responsabilidades adicionais dos pesquisadores de Educação Ambiental, permeadas por atividades pedagógicas/práticas de modos experienciais, emocionais, sensoriais e concretos de aprender/saber/investigar e trabalhar para entender a natureza da experiência intersubjetiva através de uma investigação sensível e criativa o bastante para registrar a mudança e também onde ela ocorre, recaem sobre dimensões de busca pessoal e mudança social que se dão por meio da experimentação crítica de estratégias e pedagogias de investigação do ponto de vista relacional e socioecológico. É possível indagar sobre como a pesquisa em Educação Ambiental produzida no Canadá terá respostas para os desafios políticos da justiça ecossocial global, na qual complexas questões de políticas de identidade local impactam as habitações globais da Terra, entendidas como lares. Dadas as direções locais atuais, permaneço, por ora, otimista.

\section{Referências}

BAI, $\mathrm{H}$. The Three I's for ethics as an everyday activity: Integration, intrinsic valuing, and intersubjectivity. Canadian Journal of Environmental Education, v. 9, n. 1, p. 31-46, 2004. BAKER, J. Biocentric education: A complexivist perspective on sustainability. Paper presented at the academic papers seminar: From research to practice. Trails to Sustainability: A national environmental education conference, Kananaskis, Canada, 2007.

BARKER, S. Can ecological inquiry provide a pathway to sustainability? Paper presented at the academic papers seminar: From research to practice. Trails to Sustainability: A national environmental education conference, Kananaskis, Canada, 2007.

BARRETT, M. J. Making (some) sense of feminist poststructuralism in environmental education research and practice. Canadian Journal of Environmental Education, v. 10, n. 1, p. 79-93, 2005.

Barrett, M. J. Porosity.ca. Doctoral dissertation. Regina, Canada: University of Regina, 2009.

BARRETT, M. et al. Challenges in implementing action-oriented sustainability education. In: LEAL-FILHO, ,W. (Ed.) Handbook of sustainability research. Frankfurt: Peter Lang, 2005.

BLANCHET-COHEN, N. Taking a stance: child agency across the dimensions of early adolescents' environmental involvement. Environmental Education Research, v. 14, n. 3, p. 
257-272, 2008.

BLENKINSOP, S. Seeds of green: My own Arctic copper/mine. Canadian Journal of Environmental Education, v. 11, n. 1, p. 157-165, 2006.

BONNETT, M. Education for sustainability as a frame of mind. Environmental Education Research, v. 12, n. 3-4, p. 247-264, 2006.

BONNET, M.; ELLIOTT, J. Editorial. Cambridge Journal of Education, v. 29, n. 3, p. 309311, 1999.

Brunner, D. Between the masks: Resisting the politics of essentialism. Lanham: Rowman \& Littlefield, 1998.

CHEAK, M.; VOLK, T.; HUNGERFORD, H. Molokai: An investment in children, the community, and the environment. Carbondale, IL: CISDE, 2002.

CHENEY, J. The moral epistemology of First Nations stories. Canadian Journal of Environmental Education, v. 7, n. 2, p. 88-100, 2002.

CURTHOYS, L. Find a place of one's own: Reflections on teaching in and with place. Canadian Journal of Environmental Education, 12, p. 68-79, 2007.

DAVIES, B. Subjectification: the relevance of Butler's analysis for education. British Journal of Sociology of Education. Special issue. Troubling identities: reflections on Judith Butler's work for the Sociology of Education, v. 27, n. 4, p. 425-438, 2006.

DAVIES, B.; HARRÉ, R. Positioning: The discursive production of selves. Journal for the Theory of Social Bebaviour, v. 20, n. 1, p. 43-63, 1990.

DYMENT, J.; REID, A. Breaking new ground? Reflections on greening school grounds as sites of ecological, pedagogical, and social transformation. Canadian Journal of Environmental Education, v. 10, n. 1, p. 286-301, 2005.

ELLSWORTH, E. Places of learning: media, architecture, pedagogy. New York: Routledge, 2005.

FAWCETT, L. Ethical imagining: Ecofeminist possibilities and environmental learning. Canadian Journal of Environmental Education, v. 5, n. 1, p. 114-133, 2000.

FAZIO, X.; KARROW, D. Personal communication (September 21), 2009.

FAZIO, X.; KARROW, D.; ANDRACHUK, H. Promoting environmental education through a school-university-community partnership. Paper presented at the National Science Teachers' Association Conference, Boston, MA, 2008.

FLOWERS, A. Exploring the use of positive and negative messages, images, and experiences when motivating youth to change their environmental behaviour. Paper presented at the academic papers seminar: From research to practice. Trails to Sustainability: A national environmental education conference, Kananaskis, Canada, 2007.

GOVERNMENT OF CANADA. A framework for environmental learning and sustainability in Canada. Ottawa: Environment Canada, 2002.

GRAY-DONALD, J.; SELBY, D. (Eds.). Green frontiers: Environmental educators dancing away from mechanism. Rotterdam, The Netherlands: Sense, 2008.

GREENWOOD, D. The best of both worlds: A critical pedagogy of place. Environmental Education Research, v. 14, n. 3, p. 308-324, 2008 a.

GREENWOOD, D. A critical pedagogy of place: From gridlock to parallax. Environmental Education Research, v. 14, n. 3, p. 336-348, 2008b.

GREENWOOD, D.; MCKENZIE, M. (Eds.). Context, experience, and the socioecological: Inquiries into practice. Canadian Journal of Environmental Education, 14, 2009. 
GRINDSTAFF, F. The context variable of the organic field model. In W. Peters (Ed.), Effecitve English teaching: concept, research and practice Urbana, IL: National Council of Teachers of English, 1987. (p. 45-92).

HART, P. Environmental education in Canada: Contemporary issues and future possibilities. Australian Journal of Environmental Education, 6, p. 45-66, 1990.

HART, P. Searching for meaning in children's participation in environmental education. In: JENSEN, B.; SCHNACK, K.; SIMOVSKA, V. (Eds.). Critical environmental and health education - Research issues and challenges. Copenhagen, Denmark: Research Centre for Environmental and Health, Danish University of Education, 2000.

HART, P. Teachers' thinking in environmental education: Consciousness and responsibility. New York: Peter Lang, 2003.

HART, P. Ontological/epistemological pluralism within complex contested EE/ESD landscapes: Beyond politics and mirrors. In: PETERS, M; GONZALEZ-GAUDINO, E. (Eds.), Environmental education: Identity, politics and citizenship Rotterdam, the Netherlands: Sense Publishers, 2008. (p. 25-38)

HART, P.; NOLAN, K. A critical analysis of research in environmental education. Studies in Science Education, 34, p. 1-69, 1999.

HEINTZMAN, P. Rowing, sailing, reading, discussing, praying: The spiritual and lifestyle impact of an experientially-based, graduate, environmental course. Paper presented at the academic papers seminar: From research to practice. Trails to Sustainability: A national environmental education conference, Kananaskis, Canada, 2007.

HICKORY, S. Everyday environmental ethics as comedy and story: A collage. Canadian Journal of Environmental Education, v. 9, n. 1, p. 71-81, 2004.

IOZZI, L. Research in environmental education 1971-1980. Columbus, OH: ERIC/SMEAC, 1981.

JARDINE, D. "Cutting Nature's Leading Strings": A cautionary tale about constructivism. Canadian Journal of Environmental Education, v. 10, n. 1, p. 38-51, 2005.

JICKLING, B. Environmental education: Is it more than objective science and facts? Canadian Journal of Environmental Education, v. 3, n. 1, p. 5-7, 1998.

JICKLING, B. Making ethics an everyday activity: How can we reduce the barriers? Canadian Journal of Environmental Education, v. 9, n. 1, p. 11-26, 2004.

KOOL, R. Personal construct theory and its utility for environmental educators. Paper presented at the academic papers seminar: From research to practice. Trails to Sustainability: A national environmental education conference, Kananaskis, Canada, 2007.

LATHER, P. Getting smart. Feminist research and pedagogy with/in the postmodern. New York: Routledge, 1991.

LEDUC, T.; WARKENTIN, T. Creative disruptions in the subway of critical environmental pedagogy. Canadian Journal of Environmental Education, v. 11, n. 1, p. 166-178, 2006. LIEBERMAN, G.; HOODY, L. Closing the achievement gap: Using the environment as an integrating context for learning. San Diego, CA: State Education and Environment Roundtable, 1998.

LOTZ-SISITKA, H. Environmental education research and social change: Southern African perspectives. Environmental Education Research, v. 10, n. 3, p. 291-295, 2004. MACKLIN, K., HVENEGAARD, G.; JOHNSON, P. Fostering the future: Engaging children with the natural environment by using theatre games in interpretive programs. 
Paper presented at the academic papers seminar: From research to practice. Trails to Sustainability: A national environmental education conference, Kananaskis, Canada, 2007.

MARCINKOWSKI, T. A contextual review of the 'Quantitative Paradigm' in EE research. Paper presented at a symposium Contesting paradigms in environmental education research. Annual conference of the North American Association for Environmental Education, Austin, Texas, 1990.

MAYER-SMITH, J.; BARTOSH, O. Personal communication (September 20), 2009. MCKENZIE, M. The "Willful Contradiction" of poststructural socio-ecological education. Canadian Journal of Environmental Education, v. 9, n. 1, p. 177-190, 2004.

MCKENZIE, M. The places of pedagogy: Or, what we can do with culture through intersubjective experiences. Environmental Education Research, v. 14, n. 3, p. 361-373, 2008. MCKENZIE, M. Personal communication (Sept. 21), 2009.

O'DONOGHUE, R.; RUSSO, V. Emerging patterns of abstraction in environmental education: A review of materials, methods and professional development perspectives. Environmental Education Research, v. 10, p. 3, p. 313-330, 2004.

PALMER, J. Environmental education in the 21st century: Theory, practice, progress and promise. London: Routledge, 1998.

PAYNE, P. Untimely ecophenomenological framings of environmental education research. In: DILLON, J; WALS, A; BRODY, M; STEVENSON, B. (Eds.), Handbook for research in environmental education. New York: Routledge. (In press).

PRUNEAU, D. Conception et experimentation d'un processus de formation en course demplio destine a inciter les enseignanats du prescolaire et du primaire a agier en education relative a l'environment. Unpublished doctoral dissertaton, Montreal, Canada: Laval University, 1995.

REID, A. Sensing environmental education research. Canadian Journal of Environmental Education, v. 8, n. 1, p. 9-30, 2003.

REID, A. Environmental education research: Will the ends outstrip the means? Environmental Education Research, v. 13, n. 2, p. 129-154, 2009.

REID, A.; SCOT'T, W. (Eds). Special issue: Researching education and the environment: Retrospect and prospect. Environmental Education Research, v. 12, n. (3-4), 2006.

REMPELL, J. Imagining a pedagogical watershed: Measuring how students' cognitive, affective and behavioural landscapes are shaped by multiple-grogram wetland education streams. Paper presented at the academic papers seminar: From research to practice. Trails to Sustainability: A national environmental education conference, Kananaskis, Canada, 2007.

ROBOTTOM, I. (Ed.). Environmental education: Practice and possibility. Geelong, Victoria, Australia: Deakin University Press, 1987.

ROBOTTOM, I. Critical environmental education research: Re-Engaging the debate. Canadian Journal of Environmental Education, v. 10, n. 1, p. 62-78, 2005.

ROBOTTOM, I.; HART, P. Research in environmental education: Engaging the debate. Geelong, Victoria, Australia: Deakin University Press, 1993.

RUSSELL, C.; SARICK, T.; CHANDLER, J. Queering environmental education. Canadian Journal of Environmental Education, v. 7, n. 1, p. 54-66, 2002.

SAUVÉ, L. Environmental education and education for sustainable development: A further appraisal. Canadian Journal of Environmental Education, v. 1, n. 1, p. 7-34, 1996. 
SAUVÉ, L. Environmental education between modernity and postmodernity: Searching for an integrating educational framework. Canadian Journal of Environmental Education, 4, p. 9-35, 1999.

SAUVÉ, L. Currents in environmental education: Mapping a complex and evolving. Canadian Journal of Environmental Education, v. 10, n. 1, p. 11-37, 2005.

SAUVÉ, L. Three decades of international guidelines for environment-related education: A critical hermeneutic of the United Nations discourse. Canadian Journal of Environmental Education, v. 12, n. 1, p. 33-54, 2007.

SMITH-SEBASTO, N. Potential guidelines for Conducting and reporting environmental education research: Qualitative methods of inquiry. Environmental Education Research, v. 6, n. 1, p. 9-26, 2000.

SMYTH, J. Environment and education: A view of a changing scene. Environmental Education Research, v. 12, n. 3-4, p. 247-264, 2006.

ST. PIERRE, E. The call for intelligibility in postmodern educational research. Educational Researcher, v. 29, n. 5, p. 25-28, 2000.

STEVENSON, R. Schooling and environmental education: Contradictions in purpose and practice. In I. Robottom (Ed.), Environmental education: Practice and possibility. Geelong, Victoria, Australia: Deakin University Press, 1987. (p. 69-82)

STEVENSON, R. B. Schooling and environmental/sustainability education: From discourses of policy and practice to discourses of professional learning. Environmental Education Research, v. 13, n. 2, p. 265-285, 2007.

ULIANA, K. An investigation of a community-based approach to environmental education: A case study. Unpublished master's thesis, Guelph, Canada: University of Guelph, 1996.

VAN MANEN, M. Researching lived experience: Human science for an action sensitive pedagogy. Albany, NY: State University of New York Press, 1990.

WESTON, A. Deschooling environmental education. Canadian Journal of Environmental Education, v. 1, n. 1, p. 35-46, 1996.

WESTON, A. What if teaching went wild. Canadian Journal of Environmental Education, v. 9, n. 1, p. 31-46, 2005.

WILSON MCKAY, S. Living the questions: Technology infused action research in art education. Art Education, v. 59, n. 6, p. 47-51, 2006.

ZANDVLIET, D.; BROWN, D. Framing experience on Haida Gwaii: An ecological model for environmental education. Canadian Journal of Environmental Education, v. 11, $\mathrm{n}$. 1, p. 207-219, 2006. 
Anexos

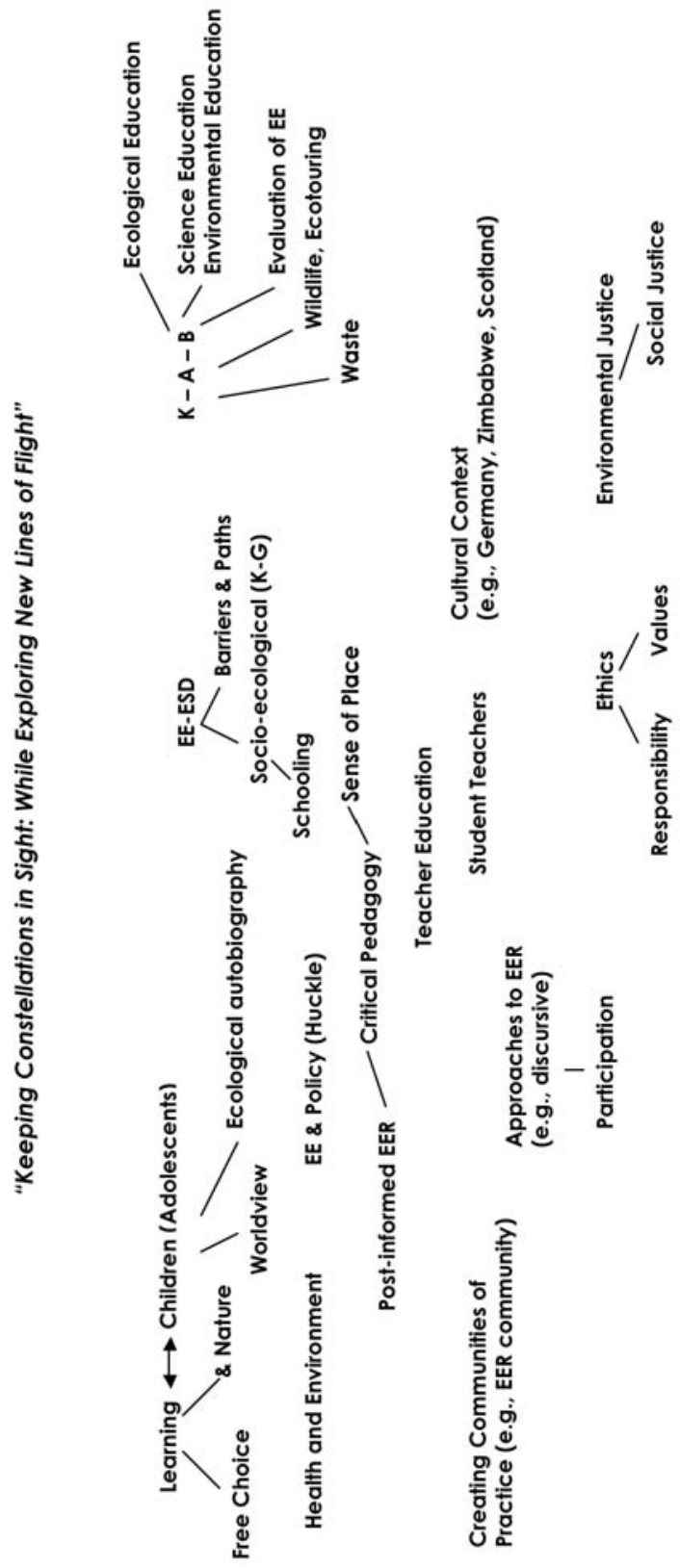

Figura 1 - "Keeping Constellations in Sight: While Exploring New Lines of Flight" 


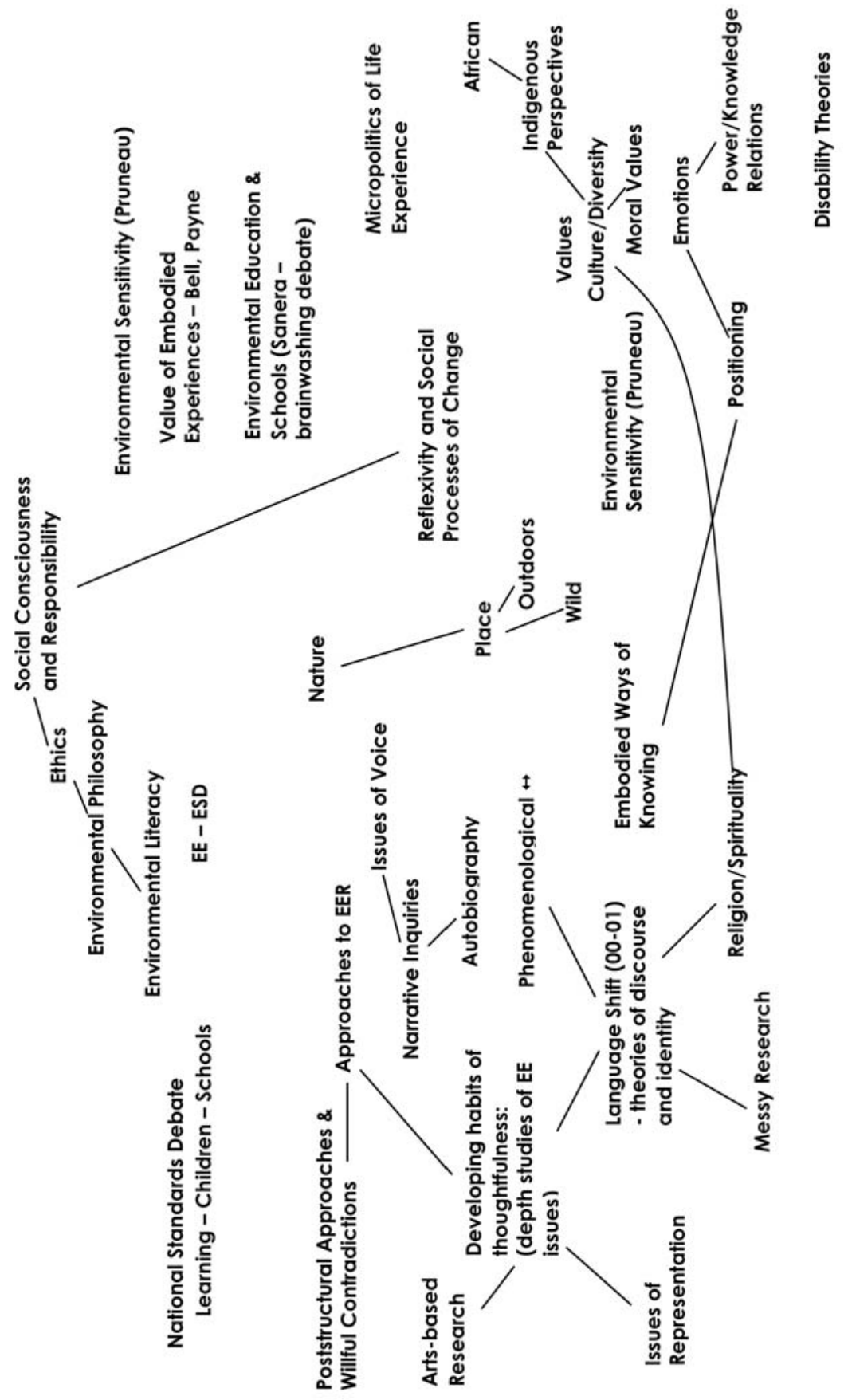

Figura 2 


\section{Notas}

${ }^{1}$ Tradução feita por Roberto Monteiro de Lima, tradutor, revisor e mestre em Lingüística pela Universidade de São Carlos (UFSCar).

Agradeço imensamente as contribuições dos seguintes educadores ambientais e pesquisadores de Educação Ambiental canadenses: Oksana Bartosh, Canadian Council on Learning; Pamela Courtenay-Hall, University of Prince Edward Island; Xavier Fazio, Brock University; Douglas Karrow, Brock University; Rick Kool, Royal Roads University; Sandy Margetts, Brandon University; Jolie Mayer-Smith, University of British Columbia; Christina McDonald, Manitoba Department of Education; Dianne Pruneau, University of Moncton; Lucie Sauvé, University of Quebec at Montreal; Gloria Snively, University of Victoria; Gareth Thomson, Alberta Council for Environmental Education;David Zandvliet, Simon Fraser University. [N.A.]

3 Congresso Mundial de Educação e Comunicação sobre Meio Ambiente e Desenvolvimento (World Congress for Education and Communication on Environment and Development), realizado em Toronto, Canadá, entre os dias 17 e 21 de outubro de 1992. [N.A.]

${ }^{4}$ Do termo inglês post-Brundtlandized, usado pelo autor do texto. Refere-se ao Relatório Brundland, denominado Nosso Futuro Comum, e publicado 1987, no qual o termo "desenvolvimento sustentável" é utilizado pela primeira vez.

${ }^{5}$ Em inglês, greenwashing. O termo refere-se à manipulação de informações para induzir a população a acreditar que determinados projetos e iniciativas, realizados sobretudo por empresas, são ecologicamente corretos. [N.T.]

\section{Agradecimentos}

The contributions of the following Canadian environmental educators and environmental education researchers is gratefully acknowledged:

Oksana Bartosh, Canadian Council on Learning

Pamela Courtenay-Hall, University of Prince Edward Island

Xavier Fazio, Brock University

Douglas Karrow, Brock University

Rick Kool, Royal Roads University

Sandy Margetts, Brandon University

Jolie Mayer-Smith, University of British Columbia

Christina McDonald, Manitoba Department of Education

Dianne Pruneau, University of Moncton

Lucie Sauvé, University of Quebec at Montreal

Gloria Snively, University of Victoria

Gareth Thomson, Alberta Council for Environmental Education

David Zandvliet, Simon Fraser University 
Recebido: 21/09/09 Aprovado: 01/10/09

Contato:

Faculty of Education University of Regina 3737, Wascana Parkway Regina Saskatchewan Canada S4S 0A2 